\title{
Fungus Resistant Transgenic Plants: Strategies, Progress and Lessons Learnt
}

\section{Aparna Islam}

Plant Breeding and Biotechnology Laboratory, Department of Botany, University of Dhaka, Dhaka-1000, Bangladesh. Email: aparnai20@yahoo.com

Key words: Antifungal proteins, Antimicrobial peptide, Induced expression, Phytopathogen, Genetic engineering

\begin{abstract}
Considerable progress has been made in identification and cloning of genes involved in plant defense responses. With the aid of plant molecular biology and biotechnology, a large number of antifungal proteins and peptides have been isolated and assessed through in vitro bioassays. Genes and gene products that are involved in signaling pathways have also been predicted. Strategies like enhancement of plant structural defense, neutralization of fungal toxins and exploitation of antifungal genes from non-plant sources have been used to produce transgenic plants. Exploitation of these approaches has shown significant reduction of fungal diseases in many cases. Moreover, using the knowledge gathered from characteristics of these transgenic plants, it has been possible to obtain better resistance. Co-expression of multiple genes rather than single, use of inducible promoters instead of constitutive ones have been shown to give superior performance of transgenic plants. Further improvement in above strategies are however still necessary because all the above approaches have only resulted in varying degree of resistance, not complete fungus tolerance.
\end{abstract}

\section{Introduction}

In March, 2001, the New York City dedicated a memorial park to the misery of hundreds of thousands of starving Irish people who immigrated to the United States while a quarter of a million of fellow countrymen died from starvation during the Irish Potato Famine of 1845 to 1847 (Moffat 2001). This is a fitting reminder of the devastation plant diseases can cause and a constant reminder to improve our agricultural system to protect our crops from such colossal losses. Even now, after adoption of various agricultural practices and agrochemicals, every year plant diseases cause approximately $12 \%$ yield loss at the field level, to which are added 9 - $20 \%$ during post-harvest stages (Agrios 1997). Among the culprits causing this huge loss, the most devastating pathogens are fungi (Pennisi 2001). 
Husbandry techniques and agrochemical usages reduce fungal inoculum and spread. But it does not improve host resistance ability. To improve disease resistance genetically, plant breeding techniques were also employed. But such a procedure is applicable only within sexually compatible species and can take up to 15 - 20 years (Rommens and Kishore 2000). As a result, co-evolution of pathogens may overthrow the success of generating resistant varieties (Cornelissen and Schram 2000). For this reason, scientists are presently engaged in generating disease resistant varieties through genetic transformation followed by conventional breeding for better protection of crops against pathogenic fungi.

Genetic engineering has the advantage of incorporating resistant genes from any species to improve disease resistance genetically (Erik 2001). With the beginning of the molecular era of plant biology in the early 1980s, many complex mechanisms that evolved in plants in response to pathogen infection have been identified. The role of multitude genes that are involved in immune responses after fungus infestation and the various pathways involved therein have been elucidated (Shah 1997, Swords et al. 1997, Bushnell et al. 1998, Evans and Greenland 1998; Honée 1999, Melchers and Stuiver 2000, Rommens and Kishore 2000). Transgenic plants have been produced with genes involved in these pathways in order to evaluate their effects in enhancing disease resistance. Prior to the application of genetic engineering techniques, genes were selected on the basis of in vitro bioassay. During these assays, toxicity of the gene product toward fungal growth or development and effectiveness of specific gene(s) in disease response pathway were assessed. Depending on such assessment potential molecules were identified for their utility in producing transgenic tolerant plants (Fig. 1).

Some of the identified potential genes or gene products are normally expressed in plants. However, it takes a relatively long time for the toxin to reach an effective concentration following pathogen invasion. Such a time lag offers an inadequate defense response towards the invading pathogen. To overcome this situation transgenic plants are made which are capable of expressing or overexpressing genes of interest at an early stage, preferably with constitutive expression throughout the plant body system to combat any pathogen invasion.

The present paper gives an overview of different strategies and progress so far made in fungus resistant transgenic plant development giving examples of representative defense gene products of each category and ends up with comments on the efforts currently under way in the optimization of antifungal gene expression in transgenic plants. 


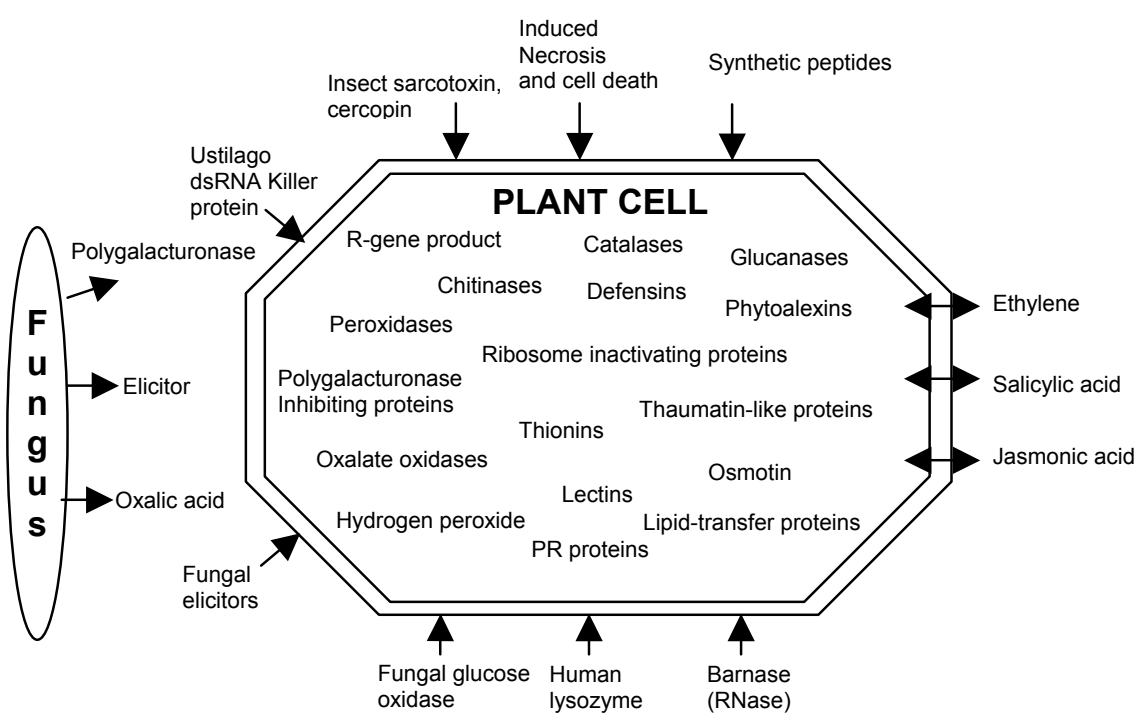

Fig. 1. Overall view of various gene products having potential antifungal activity. Within the cell all plant-derived gene products and outside the cell non-plant gene products isolated from non-plants sources are shown. Gene products that are secreted from fungi are shown around the funous (Simnlified form Punia 2001)

\section{Fungus Resistant Transgenic Plant Production:}

On the basis of known defense mechanisms, overall transgenic approaches can be grouped into seven categories (Punja 2001, Grover and Gowtham 2003).

1. Over-expression of genes that produce compounds e.g. pathogenesis-related proteins (PR proteins) and phytoalexins, which are directly toxic to pathogens or reduce their growth.

2. Expression of genes, e.g. polygalacturonase, oxalic acid and lipases that destroy or neutralize the components of pathogen arsenal.

3. Expression of gene products e.g. peroxidase and lignin, that can potentially enhance structural defense in the plants.

4. Expression of genes, e.g. elicitor, hydrogen peroxidase $\left(\mathrm{H}_{2} \mathrm{O}_{2}\right)$, salicylic acid (SA) and ethylene $\left(\mathrm{C}_{2} \mathrm{H}_{4}\right)$, that regulate signals to control plant defenses.

5. Expression of the resistance gene $(R)$ products involved in hypersensitive response (HR) for their interaction with avirulence (Avr) gene.

6. Binding or inactivation of fungal toxins thus stopping invasion of fungus by expression of $R$ gene.

7. Other strategies are production of RNAi, RNase and lysozyme . In such cases genes isolated from sources apart from plants are exploited. Available reports include introduction of double stranded RNA from viruses found in fungi (Clausen et al. 2000), genes of lysozymes cloned from human tissues 
(Nakajima et al. 1997; Takaichi and Oeda 2000), and genes isolated from fungi (Lorito et al. 1998), insects (Osusky et al. 2000) and microbes (Lorito and Scala 1999).

In the following sections all these categories will be highlighted with the advancements so far achieved and observation made.

Transgenic plants expressing pathogenesis-related proteins: Plant proteins that are produced in response to pathogen invasion and hinder growth, differentiation and multiplication of pathogens are called Pathogenesis-Related proteins or PRproteins. So far 17 families of PR-protein have been identified on the basis of their primary structure homology. The first report on developing fungus resistant transgenic plant came in 1991. Broglie et al. (1991) constitutively expressed bean chitinase in tobacco and Brassica napus to enhance resistance towards Rhizoctonia solani. Among the PR proteins hydrolytic enzymes (chitinase and glucanase), osmotins, thionins and defensins are specially importnat.

Hydrolytic enzymes: Chitinase and glucanase - The most widely used approach of developing fungus resistant plants has been over-expression of chitinases and glucanases in transgenic plants. This is because chitin and glucan comprise major components of the cell wall of most of the fungi. Over-expression of these hydrolytic enzymes in the plant cells is postulated to cause hyphal lysis, thereby inhibiting fungal growth (Mauch and Staehlin 1989). This was proved by in vitro experiments with an observation that different fungi have different degrees of sensitivity to these enzymes (Boller 1993, Yun et al. 1997). However, not all chitinase and glucanase show antifungal activity (Cornelissen et al. 1993). In addition, chitinases have no effect on some fungi such as Cercospora nicotianae, Colletotricum lagenarium and Pythium spp. as these species do not possess any chitin in their cell wall. The effectiveness of the chitinase gene in transgenic plants has been demonstrated by the reduced rate of lesion development and reduction of overall size and number of lesions upon challenge with pathogenic fungi. However, Punja reported in 2001 that there were no reports of complete control of disease (Punja 2001). In comparison with chitinase there are fewer reports of transgenic plants with glucanase activity. Combinations of both of these hydrolytic enzymes have also been expressed in transgenic plants.

Broglie et al. (1991) showed that both transgenic tobacco and Brassica napus exhibited enhanced resistance towards Rhizoctonia solani, following constitutive expression of the chitinase gene. Transgenic peanut plants following transformation with tobacco chitinase, showed partial resistance to Cercospora arachidicola (Rohini and Rao 2001). When Salehi et al. (2005) introduced bean chitinase gene in soybean driven by a constitutive promoter, they obtained a few transgenic lines that showed greater chitinase activity compared to un-transformed plants towards Rhizoctonia solani during an in vitro assay. 
Zhu et al. (1994) reported constitutive co-expression of basic chitinase from rice and acidic glucanase from alfalfa in tobacco. They observed protection against Cercospora nicotianae to be enhanced when both genes were expressed in a single plant, compared to expression of either of the single genes. Co-expression of hydrolytic enzyme with other PR-proteins has also been studied. Jach et al. (1995) regenerated transgenic tobacco plants containing barley Ribosome Inactivation Protein (RIP) in combination with either chitinase or glucanase genes. They showed that these double transgenics with the chitinase gene provide enhanced protection compared to RIP. However, they also found that protection level did not increase when glucanase and RIP were co-expressed in the transgenic plants.

Attempts were also made to evaluate these hydrolytic genes that are isolated from non-plant sources. In 1998, Lorito et al. reported lower lesion number and reduced size of lesion in Alternaria solani infection when potato plant was transformed with Trichoderma harzianeem endochitinase. However, when Broglie et al. $(1991,1993)$ tried to develop resistance in tobacco by introducing bean chitinase, no inhibition was achieved against Pythium aphanidermatum as the fungi lack chitin in their cell wall. These results highlight the importance of testing sensitivity of a fungus to a gene product before attempting transformation with the corresponding gene.

$P R$ proteins -small cysteine rich peptides: Defensins and thionins are two types of antimicrobial peptide that fall into this category. Both of these peptides are small $(\sim 5 \mathrm{kDa})$ and cysteine-rich. Both of these peptides contain eight cysteines, but differ in 3D structures which determine their antimicrobial efficiency.

Defensins (PR-12): Plant defensins exhibit antifungal activity in micro-molar concentrations (Thomma et al. 2002). They also proved to put up first line of defense in host plants against fungal pathogens. In addition, because of their small size, they can be synthesized swiftly with minimal energy input. Due to these reasons attempts were made to develop fungal resistant transgenic plants by expressing these peptides.

The first transgenic plants with defensin were regenerated by Terras et al. (1995). They transformed cDNA of Rs-AFP2 (Defensin isolated from radish seed) gene under constitutive promoter CaMV35S in tobacco to see the efficiency of the defensin peptide in a heterologous system. They found that upon artificial inoculation of Alternaria longipes the transgenic plants showed enhanced resistance. The transgene product showed typical morphological effects on the fungus. Apart from reduced disease epidemic, the lesion size was also reduced seven - eightfolds in the transgenic tobacco plant. Recently, a defensin peptide termed alfalfa antifungal peptide (alfAFP) was identified from Medicago sativa (alfalfa) (Gao et al. 2000). In vitro assays showed this new member of defensin 
peptide to have inhibitory effect on Verticillium dahliae, Alternaria solani and Fusarium culmorum, the causal agents of potato wilt, potato early blight and wheat head scab, respectively. They transformed the most widely used potato cultivar in the USA, Russet Burbank, which lacks resistance to $V$. dahliae. Under greenhouse and field trials the regenerated transgenic potato plants showed resistance to $V$. dahliae at a level or more than those obtained through conventional means based on fumigants. This was the first report of fungal resistance in commercial crop showing effective resistance even under field conditions, and the effects were assessed for two consecutive years. This report demonstrates that agronomically useful levels of fungal control can be achieved through expression of a single transgene in agricultural crops (Gao et al. 2000).

Using the potato virus X (PVX) as a vector, Saitoh et al. (2001) transformed Nicotiana benthamiana with Wasabi defensin. They reported that defensin peptide isolated from the transgenic plants showed antifungal activity against M. grisea and Botrytis cinerea. However, during in vitro assay, the isolated defensin peptide did not show antibacterial activity against $P$. cichorii. Recently, the gene encoding chickpea defensin peptide, Ca-AFP, was introduced in tobacco. The transgenic plants showed enhanced resistance to complete suppression of Alternaria solani as determined during in vitro bioassay (Islam 2004).

Thionins (PR-13): Thionins have been found to inhibit several plant pathogenic Gram-positive and Gram-negative bacteria and also fungi including Oomycetes under in vitro conditions. These observations suggested that plants containing thionins could provide fungal resistance in planta. Epple et al. (1997) transformed Arabidopsis thaliana with Arabidopsis endothionin Thi2.1 gene and found enhanced resistance in the transgenic against Fusarium oxysporum f. sp. matthiolae, whereas, the untransformed Arabidopsis showed no defense against the same fungus. This implies that each transgenic plant needs to be evaluated in a case by case manner.

Other PR Proteins: Other PR proteins that are induced either in presence of pathogen infection or under stress have also been reported to have antifungal activity. These include osmotins, thaumatin-like proteins, peroxidase, oxalate oxidase etc. There have been attempts to develop fungus resistant transgenic plants by over-expressing these genes (Jach et al. 1995, Lorito et al. 1996, Chen and Punja 2002).

Osmotin and thaumatin-like proteins (PR-5): Osmotin is a basic 24-kDa protein belonging to the PR-5 family whose members have a high degree of homology to the sweet-tasting protein thaumatin from Thaumatococcus danielli. This group of protein is triggered by several factors such as wounding, $\mathrm{NaCl}$, desiccation, ethylene, abscisic acid and various phytopathogens such as fungi and viruses. The precise function of osmotin is not clearly understood. However, the results 
of some preliminary experiments have revealed that this chemical it causes damage in the fungal cell releasing cytosolic solutes, thus causing inhibition of fungal growth (Broekaert et al. 2000). In vitro experiments showed antifungal activity against Phytophthora infestans, Candida sp., Neurospora crassa and Trichoderma reesei (Liu et al. 1994). When tested in combination with chitinase and glucanases, it enhanced their lytic activity (Lorito et al. 1996).

Nonetheless, fungi exhibit varying degrees of sensitivity to osmotin. Liu et al. (1994) reported the effects of tobacco osmotin on Phytophthora sp. in vitro and in transgenic potato. Tobacco osmotin gene has been reported to cause reduced rate of late blight infection in potato. But, in tobacco over-expression of the same gene had no effect on P. parasitica var. nicotianae.

Chen and Punja (2002) introduced thaumatin-like protein (tlp) along with another agronomically important gene, bar (herbicide resistant gene) in carrot. They obtained 45 primary transformants of which four transgenic lines showed significantly enhanced tolerance to the foliar and root pathogen Botrytis cinerea and Sclerotinia sclerotiorum under controlled environment conditions. Two of those four lines showed significantly enhanced tolerance to the herbicide phosphinothricin. These results demonstrate the feasibility of simultaneous introduction of two potentially useful agronomic traits through genetic engineering.

Ribosome inhibitory proteins (RIP): RIPs possess 28S rRNA N-glucosidase activity that inhibits the binding of 605 ribosomal subunit to elongation factor 2 , thereby terminating the elongation process of protein chain in eukaryotic ribosomes. Plant RIPs inactivate ribosomes of distantly related species and of other eukaryotes including fungi (Cornelissen and Schram 2000). Logemann et al. (1992) have shown that RIP isolated from barley, when expressed under the control of an inducible promoter, resulted in an increased protection of transgenic tobacco against Rhizoctonia solani without affecting or influencing plant growth. The level of resistance observed in these plants was higher than transgenic tobacco plants constitutively expressing exo-chitinase gene. Jach et al. (1995) developed transgenic tobacco transferring the two genes together. They introduced chitinase and RIP in one set of experiments, and in another set chitinase and glucanase genes isolated from barley, and tobacco and demonstrated that both combinations; i.e., chitinase and glucanase; and chitinase and RIP show enhanced resistance against $R$. solani in vitro than any of the genes singly. However, the best resistance was obtained from transgenics having combined expression of barley RIP gene with barley chitinase. These plants were reported to show 5\% reduction in disease development following artificial inoculation of $R$. solani (Jach et al. 1995). 


\section{Transgenic plants producing phytoalexins}

Phytoalexins are low molecular mass secondary metabolites with antimicrobial activities produced in a broad range of plant species. These are produced in plants after pathogen attack and under abiotic stresses. Production of these phytoalexins to develop fungus resistant plants has also been exploited. Many unrelated plant species produce same phytoalexins. So over-expression of such genes in unrelated plants may be fruitful to achieve the goal. Grapevine, peanut and pine synthesize the stilbene-type phytoalexin, 'resveratrol', when attacked by pathogens. This molecule was postulated to have antifungal activity. Stilbene synthase, also termed resveratrol synthase, is the enzyme that synthesizes the phytoalexin resveratrol. Thomzik et al. (1997) introduced grapevine stilbene synthase gene in tomato plants and found accumulation of the phytoalexin resveratrol (the product of stilbene synthase) shortly after fungal inoculation. The transformants showed enhanced resistance against Phytophthora infestans. No significant increase in resistance was observed in transgenic tomato plants although accumulation of resveratrol occurred after they were inoculated with Botrytis cinerea and Alternaria solani. Hain et al. (1993) introduced the stilbene synthetase gene from grapevine into tobacco plants. Expression of the transgene resulted into production of resveratrol and the transgenic plants exhibited enhanced resistance against Botrytis cinerea. However, the level of resistance obtained was not sufficient for commercial exploitation.

Production of phytotoxins metabolites, such as mycotoxins and oxalic acid by fungi has been shown to facilitate infection of host tissues followed by cell death. Degradation of these compounds by enzymes expressed in the transgenic plants could provide an opportunity to enhance resistance against diseases. Expression of trichothecene-degrading enzymes from Fusarium sporotrichioides in transgenic tobacco reduced plant tissue damage and enhanced seedling emergence in presence of trichotecene (Muhitch et al. 2000).

\section{Transgenic plant production using genes neutralizing fungal virulence products}

Fungus produces a large number of enzymes such as plant cell wall degrading enzymes (depolymerases) and toxins (e.g. oxalic acid) to degrade plant cell walls in order to enter the cells. Several strategies to engineer resistance against fungal infection have targeted the inactivation of these pathogen virulence products. Polygalacturonase inhibiting proteins (PGIP) are glycoproteins present in the cell wall of many plants and they can inhibit the activity of fungal endopolygalacturonases (Powell et al. 1994, Desiderio et al. 1997). Transgenic plants with PGIP genes were speculated to show enhanced level of protection. But very contrasting results were obtained. In transgenic tomato, expression of bean PGIP 
showed no enhancement of resistance against Fusarium, Botrytis and Alternaria (Desiderio et al. 1997); but pear PGIP expressed in tomato plants showed enhanced resistance against Botrytis (Powell et al. 2000). In an earlier study, it was shown that the PGIPs from bean plants differed in specificity to fungal polygalacturonase in vitro and the PGIP-1 that had been selected for transformation was not inhibitory (Desiderio et al. 1997). This emphasized the need of appropriate in vitro screening of PGIPs prior to undertaking transformation experiments.

Oxalic acid is one of the toxic products that fungi release inside the plant cell. Oxalate oxidases are glycoprotein that acts on oxalic acid and breakdown into $\mathrm{CO}_{2}$ and $\mathrm{H}_{2} \mathrm{O}_{2} . \mathrm{H}_{2} \mathrm{O}_{2}$ is a defense signal molecule. On one hand accumulation of $\mathrm{H}_{2} \mathrm{O}_{2}$ is expected to trigger defense response, on the other hand, it improves the tolerance of the host plant against the fungal toxin (Thompson et al. 1995). They expressed barley oxalate oxidase gene in oilseed rape enhancing its tolerance to phytotoxic effect of oxalic acid.

Some of the phytopathogenic fungi like A. alternata, secrete mannitol to quench reactive oxygen species (ROS), an activator of defense response pathway of plants. Jennings et al. (2002) showed that MTD (Mannitol dehydrogenase) in the host plant is capable to metabolizing mannitol to the non-quenching sugar mannose, thus protect plants from ROS loss and helps in triggering defense response. They showed this in transgenic tobacco by introducing MDT gene from celery. Though, MTD mediated process reported to beresponsible for enhancement of fungal resistance, this cannot be employed to all fungi as not all of them produce mannitol.

\section{Expression of structural components in transgenic plants}

From the above discussion it is clear that by introducing antifungal gene into the transgenic plants fungal resistance can be obtained only for few selective fungi. But at any point of time, plants are attacked by different pathogens including various fungi. Therefore, research is going on to develop transgenic plants that will have more durable resistance directed towards a broader spectrum of pathogens. One strategy to achieve such a goal is by inducing local cell death called apoptosis at the site of infection, which is a general defense response of plants during incompatible plant-pathogen interaction to stop the progression of the pathogen. Nicholson and Hammerschmidt (1992) reported that lignification of plant cells around sites of infection or lesions can potentially slow down the spread of the invading pathogen. The enzyme peroxidase is required for the final polymerization of phenolics derivatives into lignin and may also be involved in suberization or wound healing. The importance of phenolic compounds in defense was demonstrated in transgenic potato by Yao et al. (1995). They showed 
transgenic potatoes to be more susceptible to Phytophthora infestans due to lignin reduction in tubers. However, cucumber peroxidase in potato and tobacco anionic peroxidase in tomato had no effect on disease resistance against Fusarium sambucinum, F. oxysporum, Verticilium dahliae and Phytophthora infestance (Lagrimini et al. 1993, Ray et al. 1998). Moreover, over-expression of peroxidase gene in plants can have negative effects on their physiological parameters (Punja 2001). Overall, the results obtained so far showed less promises for enhancing disease resistance through incorporation of structure alteration genes.

\section{Activation of signal transduction pathway}

After perceiving the avr gene product, elicitors, signal cascade is trigger by activation of host activator molecules. These activator molecules then interact with signal molecules such as $\mathrm{H}_{2} \mathrm{O}_{2}$, salicylic acid (SA), jasmonic acid (JA) and ethylene thereby triggering defense responses in plants, exemplified by HR, PR proteins and phytoalexin (Heath 2000; McDowell and Dangl 2000; Shirasu and Schulze-Lefert 2000).

$\mathrm{H}_{2} \mathrm{O}_{2}$ is one of the activator molecules interacting with signal cascade and induces PR proteins, phytoalexins, SA and ethylene. Wu et al. $(1995,1997)$ reported that by introducing Aspergillus niger glucose oxidase gene in potato, delayed lesion development by Phytophthora infestans, reduced disease development by Alternaria solani and Verticillium dahliae can be achieved. However, high level of expression of these proteins can also be phytotoxic. Therefore, induction of $\mathrm{H}_{2} \mathrm{O}_{2}$ accumulation throughout the plant needs to be approached with caution.

There are many other signaling molecules such as salicylic acid (SA), jasmonic acid (JA), and ethylene (Yang et al. 1997, Dong 1998, Reymond and Farmer 1998, Dempsey et al. 1999). Evidence for the role of SA in defense response has been obtained by its overproduction in transgenic plants. Plants expressing the SA-metabolizing enzyme salicylate hydroxylase, a bacterial protein that converts SA to the inactive form catechol, are reported to hinder accumulation of high levels of SA, thereby enhancing susceptibility to pathogen infection (Gaffney et al. 1993, Delaney et al. 1994, Donofrio and Delaney 2001), and in some cases resulted in unaltered susceptibility (Yu et al. 1997). Verberne et al. (2000) showed that over-expression of SA in transgenic tobacco plants can enhance PR-protein production and provide resistance to fungal pathogens. Depending on these findings it was postulated that over-expression of the signal molecule SA may enhance resistance in host plants. These studies demonstrated that by manipulating SA levels disease resistance may be enhanced. 
Ethylene and JA appeared to act as signals in response to necrotrophic pathogen attack in plants. They are so far reported to work independently or show antagonism to SA-mediated responses (Thomma et al. 1999).

Ethylene- and extracellular PR-protein production were found to be induced by expression of cytokinins in transgenic tomato cells (Bettini et al. 1998). Insertion of anti-sense version of nitrilase 1 gene in Arabidopsis is reported to reduce the IAA level and the development of Plasmodiophora brassica-induced root galls (Neuhaus et al. 2000). Over-expression of IAA in tobacco is reported to have enhanced ethylene production and peroxidase activity and increased lignin content (Sitbon et al. 1999). However, response to disease resistance of these transgenics has not been tested.

\section{Activation of defense response by 'avr' gene products and host resistance genes}

The invading fungus releases a number of 'avr' gene products following its entry into the plant cells to establish infection. On the other hand, plant resistance genes produce molecules that have the ability to recognize these 'avr' gene products. The second phase of defense response starts when these $R$ gene and elicitor makes a complex and generate activator molecules which finally interact with signal molecules such as $\mathrm{H}_{2} \mathrm{O}_{2}$, SA, JA and ethylene.

Elicitor produced by Cladosporium fulvum is a product of virulence gene 'avrg' and De Wit (1992) proposed that if 'avr9' gene can be introduced, then broad spectrum resistance could be obtained. In 1994, Hammond-Kosack et al. showed HR response in tomato seedlings by expression of the 'avr9' transgene. Transgenic tobacco plants were made harboring a fusion between the pathogeninducible tobacco 'hsr203J' gene promoter and Phytophthora cryptogea gene encoding elicitor cryptogene in order to control the expression of 'avr9' gene only in presence of pathogen (Keller et al. 1999). They reported the expression of cryptogene to be tightly controlled; i.e., HR response was tightly controlled and only in presence of $P$. parasitica var. nicotianae. Moreover, the transgenic plants displayed enhanced resistance to few other unrelated species, such as Thielaviopsis basicola, Erysiphe cichoracearum and Botrytis cinerea. This report not only demonstrates that single gene can produce broad spectrum resistance, but also implies that when transgenes are introduced into heterologous system the effectiveness of the gene needs to be assessed very cautiously. Because the introduced gene may produces resistance towards many more untargeted, nonrelated species.

Techniques which allow determination of differential expression will result in identification of specific proteins and their relative role in fungus tolerance. Recently, Zou et al. (2005) identified nearly 4000 genes through microarray approach in soybean in response to pathogenic bacteria. Similar experiments can 
also be done to identify $\mathrm{R}$ gene in plants in order to identify genes with broad resistance capacity.

\section{Antifungal proteins from non-plant sources}

All organisms produce antimicrobial proteins (AMPs) to protect themselves from fungal pathogens. To find out effective antifungal proteins and to develop transgenics with better fungal resistance, various non-plant sources have also been exploited. Among these mycoparasitic fungi, viruses infecting fungus, cationic antimicrobial peptides from insects and bacteria, human gene and synthetic peptides deserve special mention.

AMP from mycoparasitic fungi: Trichoderma harzianum is a mycoparasite, which has an antagonistic effect on fungi and cause lyssis of the delicate hyphal tip and chitin wall of mature hyphae and conidia. The endochitinase gene was isolated from Trichoderma harzianum and transferred to tobacco and potato by Agrobacterium tumefacience by Lorito and his colleagues (1998). Some of the transgenic lines, they developed were found to be highly tolerant or completely resistant to certain foliar (e.g. Alternaria alternate, A. solani, B. cinerea) and soil borne pathogens (e.g. R. solani).

Endochitinase gene from another mycoparasitic fungi Trichoderma virens was introduced by Emani et al. (2003) into cotton and tobacco plants. In both species, the endochitinase activity was observed throughout the plant body. When homozygous $\mathrm{T}_{2}$ plants of the highly expressing cotton lines were tested against a soil-borne pathogen, Rhizoctonia solani and a foliar pathogen, Alternaria alternate, they showed significant resistance to both pathogens.

AMP from Virus Infecting Fungi: Similarly, Clausen and co-workers regenerated transgenic wheat by transferring an antifungal gene KP4 of nonplant origin under the control of the ubiquitin promoter of maize (Clausen et al. 2000). Koltin and Day (1975) showed that when Ustilago maydis strain ATCC 32357 is infected by the double stranded RNA $U$. maydis virus, the fungus secretes a protein, KP4 (Killer Protein $\underline{4}$ ). This KP4 exhibits antifungal activity towards U. tritici, which causes loose smut disease in wheat. Upon discovering the biological characteristics of KP4 protein, Clausen et al. (2000) transferred this gene into Swiss wheat varieties which are highly susceptible to smut infection. Under greenhouse conditions these transgenic wheat lines exhibited stable antifungal activity over many generations and reduced reproduction rate of $U$. tritici (Clausen et al. 2000).

AMP from Insects: Insect cecropins are members of a peptide family consisting of small, highly basic, $\alpha$-helical antibacterial peptides. Cecropin A isolated from giant silk moth, Hyalophora cecropia are ca. 35 amino acids long, and shows antimicrobial activity in vitro. Melittin is another peptide which was 
isolated from bee venom and has a strong hemolytic activity, making it a highly unsuitable candidate for transgenic applications. Through molecular modelling and engineering of peptides, a chimeric peptide CEMA was made demonstrating the same antimicrobial activity. But since CEMA also showed lytic capacity, this engineered molecule was not recommended for transgenic use. Osusky and coworkers (2000) then modified CEMA further and developed MsrA1 that had in vitro antimicrobial activity, but no lytic effect. They transformed two potato varieties, Desiree and Russet Burbank, with 'msrA1' driven by a constitutive promoter and found that transgenic potato lines were resistant against bacterial (Erwinia sp.) as well as fungal pathogens (Fusarium sp. and Phytophthora sp.). However, constitutive expression of ' $m s r A 1$ ' in Russet Burbank potato caused lesion-mimic phenotype. On the contrary, expression of ' $m s r A 1$ ' in the transgenic Desiree variety had virtually no deleterious effects on the morphology or yield of plants and tubers. This observation demonstrates the importance of assessing every transformation event in a case by case manner. Each evaluation needs to include from morphology of transgenic plants to effectiveness of transgenes in those transformants.

Human lysozyme gene: Nakajima and coworkers (1997) introduced human lysozyme gene into tobacco under CaMV35S promoter though Agrobacteriummediated method. The introduced human lysozyme gene product in the transgenic tobacco plants showed enhanced resistance against Erysiphe cichoracearum by reducing mycelial growth and conidia formation. Growth of the phytopathogenic bacteria Psedomonas syringae was also reduced. This report makes it possible to use the human lysozyme gene to protect crops against fungal diseases.

Two-component system: From Bacillus amyloliquefaciences two proteins were isolated, namely, 'barnase', a protein with RNase activity and 'barstar' inactivitor of 'barnase'. Strittmatter et al. (1995) introduced both these protein encoding genes into potato to see their effectiveness in fungal resistance. Barnase gene was placed under the control of pathogen-inducible potato promoter so that its activity to kill the cell was restricted only at the site of pathogen invasion. To avoid cell death due to unwanted expression of barnase gene, the barstar gene was expressed constitutively throughout the plant. Cells were killed only when barnase activity was higher than that of barstar. Transgenic potato plants showed leaf tissue necrosis at the $P$. infestans inoculation site. Though disease symptoms were reduced, the transgenics were not tested at the field level.

Synthetic AMP gene: Extensive search for antimicrobial peptide to be used in generating transgenic plant have lead to development of several synthetic peptides. Ali and Reddy (2000) reported effectiveness of four synthetic cationic peptides, namely, pep6, pep7, pep11 and pep20. All these peptides exhibited 
complete inhibition of two important pathogenic fungi $P$. infestans and A. solani during in vitro assay. Oard et al. (2004) compared antifungal activity of 12 natural and synthetic peptides. Of the tested peptides, natural peptide purothionin showed the strongest inhibitory activity followed by synthetic peptide, D4E1 against $R$. solani. Rajasekaran et al. (2005) transformed D4E1 peptide in cotton. In vitro assays with crude leaf protein extracts from $\mathrm{T}_{0}$ and $\mathrm{T}_{1}$ plants showed that D4E1 was expressed at sufficient levels to inhibit the growth of $F$. verticillioides and $V$. dahliae. In planta assays with the fungal pathogen, Thielaviopsis basicola transgenic $T_{1}$ seedlings showed a significant reduction in disease symptoms and increased seedling fresh weight, demonstrating tolerance to the fungal pathogen. There are more reports on efficiency of synthetic peptides in controlling fungal pathogens. It is now matter of time to see the efficiency of those peptides in transgenic plants.

\section{Optimization of antifungal gene expression in transgenic plants}

All the strategies mentioned above concentrate on introduction and overexpression of antifungal genes to make transgenic plants to combat fungal infection. In most of the cases the antifungal genes have been introduced under constitutive expression resulting in the continuous expression of transgenes. So, the ultimate success of a transgenic plant to inhibit fungal infection depends on the expression level of the transgene(s) introduced in it.

In many cases, it was observed that the level of expression in the transgenic plants is not enough to inhibit fungal infestation (Hain et al. 1993). It is therefore imperative that emphasis is directed to express transgenes at a level effective for fungal inhibition. A word of caution against the use of cationic antifungal proteins. They do express antimicrobial properties but at the same time induce plant cell damage and cause deleterious effects on plant growth and development (Honée et al. 1995). Osusky and co-workers (2000) reported lesionmimicked phenotype in transgenic potato plants when they used a small synthetic peptide, ' $m s r A 1$ ', to obtain broad-spectrum fungal resistance. Under constitutive promoter CaMV35S, transgenic tomato was also reported to die when transformed with elicitor gene 'avrg' to produce fungal resistant plants (Honée et al. 1995). Although $\mathrm{T}_{0}$ generation was morphologically normal, Anad et al. (2003) reported necrotic lesions containing dead cells in $\mathrm{T}_{2}$ and subsequent generations, when the wheat transgenic lines were homozygous for the transgenes (co-expression of chitinase and glucanase). In contrast, lesions were not observed in hemizygous transgenic lines or lines silenced for transgene expression, indicating a requirement for high levels of transgene expression for the development of the lesioned phenotype. 
In light of these observations, attempts are now made to develop transgenic plants with regulated or tissue-specific expression of transgenes in order to avoid such deleterious effects of putatively harmful transgene products as well as to minimize the loss of energy due to continuous production of transgene products. Yevtushenko et al. (2005) constructed a plant transformation vector with transcriptional fusion between the pathogen-responsive win3.12T promoter from poplar and the gene encoding the CEMA (cercopin A-melitin hybrid peptide). When they evaluated this promoter-transgene combination in transgenic tobacco, an enhanced plant resistance was observed. Transgene expression in leaves was increased following either fungal infection or mechanical wounding, followed by an accumulation of CEMA transcripts throughout the plant body and positively correlated with the number of transgene insertions. Moreover, the expression level of the CEMA peptide was sufficient to confer resistance against F. solani in transgenic tobacco. Most importantly, accumulation of CEMA peptide in transgenic tobacco had no deleterious effect on plant growth and development. This is the first report showing the application of a heterologous pathogeninducible promoter to direct the expression of an antimicrobial peptide in plants. Earlier similar attempts were made but with pathogen-inducible promoter. Transgenic tobacco plants were made harbouring a fusion product between the pathogen-inducible tobacco ' $h s r 203 J^{\prime}$ gene promoter in combination with cryptogene elicitor encoded by Phytophthora cryptogea. The object of this exercise was to control the expression of transgene only in presence of the pathogen, as continuous expression 'avr9' gene leads to premature death of the transgenics (Keller et al. 1999). The transgenic tobacco plants regenerated with this homologous pathogen-inducible promoter were reported to have tightly controlled expression of the transgene only in presence of the pathogen.

A second approach for antifungal gene expression can be tissue-specific expression of the transgenes. Altpeter et al. (2005) attempted epidermis-specific expression of a PR protein in transgenic wheat. They developed a novel epidermis-specific promoter by fusion of $2.3 \mathrm{~kb}$ fragment of wheat GstA1 promoter with an intron-containing part of wheat WIR1a gene. When this promoter-intron combination was used to over-express TaPERO peroxidise, it showed enhanced resistance against powdery mildew. This suggests that wheat GstA1 promoter in combination with WIR1a intron is a useful approach to confer fungal disease resistance in cereals.

Expression and accumulation of antimicrobial proteins at extra-cellular space where the target fungi invade is another strategy to improve resistance. As two or more antifungal genes give better response, Francois et al. (2002) introduced a cleavable chimeric polyprotein in Arabidopsis by linking two defensin peptides, DmAMP1 and RsAFP2, with a 'linker peptide' at the downstream of a 'leader 
sequence'. They reported cleavage of the chimeric polypeptide in transgenic Arabidopsis plants and secretion of individual defensins into the extracellular space. Moreover, the expressions of these small AMPs in transgenic plants were higher than expression of any one of these AMPs in singly transformed plants. In in vitro assay the purified proteins from the transgenic plants showed antifungal activity. This report shows that polyprotein expression strategy can be a way to boost expression levels of small proteins.

\section{Conclusion}

Fungal pathogens cause numerous diseases ranging from rust, smut, blight mildew to many more kinds. These diseases not only cause yield loss but quality is also reduced. Moreover, accumulation of mycotoxin in our food cause health hazard. Based on the available knowledge of plant-pathogen interaction several strategies have evolved to improve fungal resistance in plant species. In the 1990s enormous work has been carried out to identify potential genes and gene products involved in plant resistance. Extensive evaluation of such genes through transgenic plant approach was also carried out during this period.

Unfortunately, a major portion of this research involved production of transgenics in model system, tobacco. As a result much progress has not been attained in regenerating transgenic plants in economically important crops. Moreover, most of the studies were restricted within in vitro bioassay. Some transgenics have been taken to greenhouse for evaluation. But, there were only a few reports on field evaluation and commercialisation of these plants. One of the reasons for this is inadequate level of resistance found in the lab tests. Diseasemimic phenotype production in the transgenic plants due to transgene overexpression is another drawback. Again stability of transgenes for durable resistance is another challenge to meet.

To overcome these limitations innovative approaches such as pathogen induced promoter usage and identification of genes conferring broad spectrum resistance are now under study.

Enhancement of fungal resistance through transgenic approach is largely restricted within few phytopathogenic fungi like $P$. infestans, $V$. dahliae, A. solani, $R$. solani etc. But as there is about 10,000 plant-pathogenic species attention needs to be given to develop resistance towards other fungi as well. Our experience with transgenic plants have already shown that though some time transgenes were inserted for specific pathogen(s), resistance was achieved in many unrelated species as well. So, during evaluation two things needs to in mind, evaluation of resistance against target fungi and evaluation of non-target pathogenic or symbiotic fungi. This assessments needs to be performed for each 
transgenic-host species/variety as same transgene can act differently in different varieties of the same species.

Along with these scientific issues, there are obvious questions involved with safety and public acceptance. Biosafety issues include food and feed safety for human and animals, allergicity, potential spread of genes to wild relatives and development of super-weeds, effects on non-target organisms and ecounfriendly effects on the environment. So, although ground-breaking work has been done in the leading laboratories, there is a long way to go to obtain transgenic plants with significant resistance capacity.

\section{References}

Agrios GN (1997) Plant Pathology. Academic Press, California, pp. 635.

Ali GS and Reddy ASN (2000) Inhibition of fungal and bacterial pathogens by synthetic peptides: in vitro growth inhibition, interaction between peptides and inhibition of disease progression. Mol. Plant Microbe Inter. 13: 847-859.

Altpeter F, Varshney A, Abderhalden O, Douchkov D, Sautter C, Kumlehn J, Dudler R and Schweizer P (2005) Stable expression of a defense-related gene in wheat epidermis under transcriptional control of a novel promoter confers pathogen resistance. Plant Mol. Biol. 57(2): 271-283.

Anand A, Schmelz EA and Muthukrishan S (2003) Development of lesion-mimic phenotype in a transgenic wheat line overexpressing genes for pathogenesis-related (PR) proteins in dependent on salicylic acid. Mol. Plant Microbe Interact. 16(10): 916925.

Bettini, P, Cosi E, Pellegrini MG, Turbanti L, Vendramin GG, and Buiatti M (1998) Modification of competence for in vitro response to Fusarium oxysporum in tomato cells. 3. PRprotein gene expression and ethylene evolution in tomato cell lines transgenic for phytohormone-related bacterial genes. Theor. Appl. Genet. 97: 575-583.

Boller T (1993) Antimicrobial functions of the plant hydrolysases, chitinases and B-1,3glucanases. In: Mechanisms of plant defense responses. Fritig B. and Legrand M. (Eds.) Kluwer Academic Press, Dordrecht, pp. 391-400.

Broekaert WF, Terras FRG and Cammue BPA (2000) Induced and preformed antimicrobial proteins. In: Mechanism of resistance to plant diseases, Slusarenko AJ, Fraser RSS and van Loon LC (Eds.), Kluwer Academic Publishers, London, pp. 371478.

Broglie K, Chet I, Holliday M, Cressman R, Biddle P, Knowlton S, Mauvais CJ and Broglie R (1991) Transgenic plants with enhanced resistance to the fungal pathogen Rhizoctonia solani. Science 254: 1194-1197.

Broglie R, Broglie K, Roby D and Chet I (1993) Production of transgenic plants with enhanced resistance to microbial pathogens. In: Transgenic plants. Vol. 1, Kung SD and R. Wu (Eds.), Academic Press, New York. pp. 265-276.

Bushnell WR, Somers DA, Giroux RW, Szabo LJ and Zeyen RJ (1998) Genetic engineering of disease resistance in cereals. Can. J. Plant Pathol. 20: 137-149. 
Chen WP and Punja ZK (2002) Transgenic herbicide- and disease-tolerant carrot (Daucus carota L.) plants obtained through Agrobacterium-mediated transformation. Plant Cell Report 20: 929-935.

Clausen M, Kräuter R, Schachermayr G, Potrykus I and Sautter C (2000) Antifungal activity of virally encoded gene in transgenic wheat. Nature Biotechnology 18: 446449.

Cornelissen Ben JC and Melchers LS (1993) Strategies for control of fungal diseases with transgenic plants. Plant Physiol. 101: 709-712.

Cornelissen BJC and Schram A (2000) Transgenic approaches to control epidemic spread of diseases. In: Mechanism of resistance to plant diseases, Slusarenko AJ, Fraser RSS and van Loon LC (Eds.), Kluwer Academic Publishers, London, pp. 576-599.

De Wit PJGM (1992) Molecular characterization of gene-for-gene system in plants-fungus interactions and application of avirulence gene in control of plant pathogens. Annu. Rev. Phytopathol. 30: 391-418.

Delaney TP, Uknes S, Vernooij B, Friedrich L, Weymann K, Negrotto D, Gaffney T, Gut-Rella M, Kessman H, Ward E and Ryals J (1994) A central role of salicylic acid in plant disease resistance. Science 266: 1247-1250.

Dempsey DA, Shah J and Klessig DF (1999) Salicylic acid and disease resistance in plants. Crit. Rev. Plant Sci. 18: 547-575.

Desiderio A, Aracri B, Leckie F, Mattei B, Salvi G, Tigelaar H, Van Roekel JSC, Baulcombe DC, Melchers LC, De Lorenzo G and Cervone F (1997) Polygalacturonase-inhibiting proteins (PGIPs) with different specificities are expressed in Phaseolus vulgaris. Mol. Plant-Microbe Interact. 10: 852-860.

Dong X (1998) SA, JA, ethylene and disease resistance in plants. Curr. Opin. Plant Biol. 1: 316-323.

Donofrio NM and Delaney TP (2001) Abnormal callose response phenotype and hypersusceptibility to Peronospora parasitica in defense-compromised Arabidopsis nim 1-1 and salicylate hydroxylase-expressing plants. Mol. Plant-Microbe Interact. 14: 439-450.

Emani C, Garcia JM, Lopata-Finch E, Pozo MJ, Uribe P, Kim DJ, Sunilkumar G, Cook DR, Kenerley CM and Rathore KS (2003) Enhanced fungal resistance in transgenic cotton expressing an endochitinase gene from Trichoderma virens. Plant Biotech. J. 1:321-336.

Epple P, Apel K and Bohlmann H (1997) Overexpression of an endogenous thionin enhances resistance of Arabidopsis against Fusarrium oxysporum. Plant Cell 9: 509-520.

Erik A. van der Biezen (2001) Quest for antimicrobial genes for engineering diseaseresistant crops. Trends in Plant Sci. 6: 89-91.

Evans IJ and Greenland AJ (1998) Transgenic approaches to disease protection: applications of antifungal proteins. Pestic. Sci. 54: 353-359.

Francois IEJA, Bolle MFCDe, Dwyer G, Goderis JWMI, Woutors PFJ, Verhaert PD, Proost P, Schaaper WMM, Cammue BPA and Broekaert WF (2002) Transgenic Expression in Arabidopsis of a polyprotein constract leading to production of two diffeent antimicrobial proteins. Plant Physiol. 128: 1346-1358. 
Gaffney T, Friedrich L, Vernooij B, Negrotto D, Nye G, Uknes S, Ward E, Kessmann H and Ryals J (1993) Requirement of salicylic acid for the induction of systemic acquired resistance. Science 261: 754-756.

Gao AG, Hakimi SM, Mittanck CA, Wu Y, Woerner BM, Stark DM, Shah DM, Liang J and Rommens CMT (2000) Fungal pathogen protection in potato by expression of a plant defensin peptide. Nat. Biotech. 18:1307-1310.

Grover A and Gawthaman R (2003) Strategies for development of fungus-resistant transgenic plants. Curr. Sci. 84: 330-340.

Hain R, Reif HJ, Krause E, Langebartels R, Kindl H, Vornam B, Wiese W, Schmeltzer E, Schreier PH, Stöker RH and Stenzel K (1993) Disease resistance results from foreign phytoalexin expression in a novel pplant. Nature 361: 153-156.

Hammond-Kosak KE, Harrison K and Jones JDG (1994) Developmentally regulated cell death on expression in a novel plant. Proc. Natl. Acad. Sci. USA 91: 10445-10449.

Heath MC (2000) Hypersensitive response-related death. Plant Mol. Biol. 44: 321-334.

Honée G (1999). Engineered resistance against fungal pathogens. Eur. J. Plant Pathol. 105: 319-326.

Honée G, Melchers LS, Vleeshouwers VGAA, Van Roekel JSC and Wit JGMD (1995) Production of the AVR9 elicitor from the fungal pathogen Cladosporium fulvum in transgenic tobacco and tomato plants. Plant Mol. Biol. 29: 909-920.

Islam, A. (2004). Role of a small cysteine-rich antifungal protein isolated from chickpea in host defense mechanism. PhD Thesis, International Centre for Genetic Engineering and Biotechnology (I.C.G.E.B.), Jawaharlal Nehru University, pp. 129.

Jach G, Görnhardt B, Mundy J, Logemann J, Pinsdorf E, Leah R, Schell J and Mass C (1995) Enhanced quantitative resistance against fungal disease by combinatorial expression of different barley antifungal proteins in transgenic tobacco. Plant J. 8: 97109.

Jennings DB, Daub ME, Pharr DM and Williamson JD (2002) Constitutive expression of a celery mannitol dehydrogenase in tobacco enhances resistance to the mannitolsecreting fungal pathogen Alternaria alternata. Plant J 32: 41-49.

Keller H, Pamboukdjian N, Ponchet M, Poupet A, Delon R, Verrier JL, Roby D and Ricci P (1999) Pathogen-induced elicitin production in transgenic tobacco generates a hypersensitive response and nonspecific disease resistance. Plant Cell 11:223-235.

Koltin Y and Day PR (1975) Specificity of Ustilago maydis killer proteins. Appl. Microbiol. 30: 694-696.

Lagrimini, LM, Burkhart W, Moyer M and Rothstein S (1993) Molecular cloning of complementary DNA encoding the lignin-forming peroxidase from tobacco: molecular analysis and tissue-specific expression. Proc. Natl. Acad. Sci. USA 84: $7542-$ 7546.

Liu D, Raghothama KG, Hasegawa PM and Bressan R (1994) Osmotin overexpression in potato delays development of disease symptoms. Proc. Natl. Acad. Sci. U.S.A. 91: 1888-1892.

Logemann J, Jach G, Tommerup H, Mundy J and Schell J (1992) Expression of a barley ribosome-inactivating protein protection in transgenic tobacco plants. Bio/Technology 10:305-308. 
Lorito M and Scala F (1999) Microbial genes expressed in transgenic plants to improve disease resistance. J. Plant Pathol. 81: 73-88.

Lorito M, Woo SL, D'Ambrosio M, Harman GE, Hayes CK, Kubicek CP and Scala F, (1996) Synergistic interaction between cell wall degrading enzymes and membrane affecting compound. Mol. Plant-Microbe Interact. 9: 206-213.

Lorito M, Woo SL, Fernandez IG, Colucci G, Harman GE, Pintor-Toro JA, Filippone E, Muccifora S, Lawerence CB, Zoina A, Tuzun S and Scala F (1998) Gene from mycoparasitic fungi as a source for improving plant resistance to fungal pathogens. Proc. Natl. Acad. Sci. USA 95: 7860-7865.

Mauch F and Staehelin LA (1989) Functional implications of the subcellular localization of ethylene-induced chitinase and B-1,3-glucanase in bean leaves. Plant Cell. 1: 447457.

McDowell JM and Dangl JL (2000) Signal transduction in the plant immune response. Trends Biochem. Sci. 25: 79-82.

Melchers LS and Stuiver MH (2000) Novel genes for disease resistance breeding. Curr. Opin. Plant Biol. 3: 147-152.

Moffat AS (2001) Finding new ways to fight plant diseases. Science 292: 2270-2273.

Muhitch MJ, McCormick SP, Alexander NJ and Hohn TM (2000) Transgenic expression of the TRI 101 or PDR 5 gene increases resistance of tobacco to the phytotoxic effects of the trichothecene 4,15-diacetoxyscirpenol. Plant Sci. 157: 201-207.

Nakajima H, Muranaka T, Ishige K, Akutsu F and Oeda K (1997) Fungal and bacterial disease resistance in transgenic plants expressing human lysozyme. Plant Cell Rep. 16: 674-679.

Neuhaus K, Grsic-Rausch S, Sauerteig S and Ludwig-Müller J (2000) Arabidopsis plants transformed with nitrilase 1 or 2 in antisense direction are delayed in clubroot development. J. Plant Physiol. 156: 756-761.

Nicholson RL and Hammerschmidt R (1992) Phenolic compounds and their role in disease resistance. Annu. Rev. Phytopathol. 30: 369-389.

Oard S, Rush MC and Oard JH (2004) Characterization of antimicrobial peptides against a US strain of the rice pathogen Rhizoctonia solani. J. of Applied Microbiol. 97: 169.

Osusky M, Zhou G, Osuska L, Hancock RE, Kay WW and Misra S (2000) Transgenic plants expressing cationic peptide chimeras exhibit broad-spectrum resistance to phytopathogens. Nat. Biotech. 18: 1162-1166.

Pennisi E (2001) The push to pit genomics against fungal pathogens. Science 292: 22732274.

Powell ALT, Stotz HU, Labavitch JM and Bennett AB (1994) Glycoprotein inhibitors of fungal polygalacturonases. In: Advances in molecular genetics of plant-microbe interactions. Vol. 3. Daniels MJ, Downie JA and Osbourn AE (Eds.). Kluwer Academic Publishers, Dordrecht. pp. 399-402.

Powell ALT, Van Kan J, ten Have A, Visser J, Greve LC, Bennett AB and Labavitch JM (2000) Transgenic expression of pear PGIP in tomato limits fungal colonization. Mol. Plant Microbe Interact. 13: 942-950.

Punja ZK (2001) Genetic engineering of plants to enhance resistance to fungal pathogens a review of progress and future prospects. Can. J. Plant Pathol. 23: 216-235. 
Rajasekaran K, Cary JW, Jaynes JM and Cleveland TE (2005) Disease resistance conferred by the expression of a gene encoding a synthetic peptide in transgenic cotton (Gossypium hirsutum L.) plants. Plant Biotech. J. 3: 545.

Ray H, Douches DS and Hammerschmidt R (1998) Transformation of potato with cucumber peroxidase: expression and disease response. Physiol. Mol. Plant Pathol. 53: 93-103.

Reymond P and Farmer EE (1998) Jasmonate and salicylate as global signals for defense gene expression. Curr. Opin. Plant Biol. 1: 404-411.

Rohini VK and Rao KS (2001) Transformation of peanut (Arachis hypogaea L.) with tobacco chitinase gene: variable response of transformants to leaf spot disease. Plant Sci. 160: 889-898.

Rommens CM and Kishore GM (2000) Exploiting the full potential of disease-resistance genes for agricultural use. Curr. Opin. Biotechnol. 11: 120-125.

Saitoh H, Kiba A, Nishihara M, Yamamura S, Suzuki K and Terauchi R (2001) Production of antimicrobial defensin in Nicotiana benthamiana with potato virus $\mathrm{X}$ vector. Mol. Plant-Microbe Interact. 14: 111-115.

Salehi A, Mohammadi M, Okhovvat SM and Omidi M (2005) Chitinase gene transformation through Agrobacterium and its expression in soybean in order to induce resistance $€$ to root rot caused by Rhizoctonia solani. Commun. Agric. Appl. Biol. Sci. 70(3): 399-406.

Shah DM (1997) Genetic engineering for fungal and bacterial diseases. Curr. Opin. Biotechnol. 8: 208-214.

Shirasu K and Schulze-Lefert P (2000) Regulators of cell death in disease resistance. Plant Mol. Biol. 44: 371-385.

Sitbon F, Hennion S, Little CHA and Sundberg B (1999) Enhanced ethylene production and peroxidase activity in IAA overproducing transgenic tobacco plants is associated with increased lignin content and altered lignin composition. Plant Sci. 141: 165-173.

Strittmatter J Janssens, Opsomer C and Botterman J (1993) Inhibition of fungal disease development in plants by engineering controlled cell death. J. Bio/Technology, 13: 1085-1089.

Swords KMM, Liang J and Shah DM (1997) Novel approaches to engineering disease resistance in crops. In: Genetic engineering. Vol. 19. Setlow JK (Ed.) Plenum Press, New York. pp. 1-13.

Takaichi M and Oeda K (2000) Transgenic carrots with enhanced resistance against two major pathogens, Erysiphe heraclei and Alternaria dauci. Plant Sci. 153: 135-144.

Terras FRG, Eggermont K, Kovaleva V, Raikhel NV, Osborn RW, Kester A, Rees SB, Torrekens S, Leuven FV, Vanderleyden J, Cammue BPA and Broekaert WF (1995) Small cystein-rich antifungal proteins from radish: their role in host defense. Plant Cell 7: 573-588.

Thomma BPHJ, Cammue BPA and Thevissen (2002) Plant defensins. Planta 216: 193-202.

Thomma BPHJ, Eggermont K, Tierens KFMJ and Broekaet WF (1999) Requirement of function ethylene-insensitive 2 gene for efficient resistance of Arabidopsis to infection by Botrytis cinerea. Plant Physiol. 121: 1093-1101. 
Thompson C, Dunwell JM, Johnstone CE, Lay V, Ray J, Schmitt M, Watson H and Nisbet G (1995) Degradation of oxalic acid by transgenic oilseed rape plants expressing oxalate oxidase. Euphytica 85: 169-172.

Thomzik JE, Stenzel K, Stőcker R, Schreier PH, Hain R and Stahl DJ (1997) Synthesis of a grapevine phytoalexin in transgenic tomato (Lycopersicon esculentum Mill) conditions resistance against Phytophthora infestans. Physiol. Mol. Plant Pathol. 51: 265-278.

Verberne MC, Verpoorte R, Bol JF, Mercado-Blanco J and Linthorst HJM (2000) Overproduction of salicylic acid in plants by bacterial transgenes enhances pathogen resistance. Nat. Biotechnol. 18: 779-783.

Wu G, Shortt BJ, Lawrence EB, Levine EB, Fitzsimmons KC and Shah DM (1995) Disease resistance conferred by expression of gene encoding $\mathrm{H}_{2} \mathrm{O}_{2}$-generating glucose oxidase in transgenic potato plants. Plant Cell 7: 1357-1368.

Wu G, Shortt BJ, Lawrence EB,Leon J, Fitzsimmons KC, Levine EB, Raskin I and Shah DM (1997) Activation of host defence mechanisms by elevated production of $\mathrm{H}_{2} \mathrm{O}_{2}$ in transgenic plants. Plant Physiol. 115: 427-435.

Yang Y, Shah J and Klessig DF (1997) Signal perception and transduction in plant defense responses. Genes Dev. 11: 1621-1639.

Yao K, De Luca V and Brisson N (1995) Creation of a metabolic sink for tryptophan alters the phenylpropanoid pathway and the susceptibility of potato to Phytophthora infestans. Plant Cell 7: 1787-1799.

Yevtushenko DP, Romero R, Forward BS, Hancock RE, Kay WW and Misra S (2005) Pathogen-induced expression of a cecropin A-melittin antimicrobial peptide gene confers antifungal resistance in transgenic tobacco. J. Exp. Bot. 56(416):1685-1695.

Yu D, Liu Y, Fan B, Klessig DF and Chen Z (1997) Is the high basal level of salicylic acid important for disease resistance in potato? Plant Physiol. 115: 343-349.

Yun DJ, Bressan RA and Hasegawa PM (1997) Plant antifungal proteins. In: Plant Breeding Reviews. Vol. 14. Janick J (Ed). John Wiley and Sons, New York, pp. 39-88.

Zhu Q, Maher EA, Masoud S, Dixon RA and Lamb CJ (1994) Enhanced protection against fungal attack by constitutive co-expression of chitinase and glucanase genes in transgenic tobacco. Bio/Technology 12: 807-812.

Zou J, Rodriguez-Zas S, Aldea M, Li M, Zhu J, Gonzalez DO, Vodkin LO, DeLucia E and Clough SJ (2005) Expression Profiling Soybean Response to Pseudomonas syringae Reveals New Defense-Related Genes and Rapid HR-Specific Downregulation of Photosynthesis. Mol. Plant-Microbe Interac. 18: 1161-1174. 